\title{
THE CORRELATION BETWEEN CHERRY PICKING AND THE DISTANCE THAT CONSUMERS TRAVEL TO DO GROCERY SHOPPING
}

Louise van Scheers and MC Cant

Marketing and Retail, University of South Africa

\begin{abstract}
Retailers often use price promotions to discriminate between consumers who can shift purchases over time and those who cannot. Retailers consistently tend to charge lower prices than necessary, pricing defensively to prevent loyal customers from cherry picking, or shifting to competitors. Knowledge about cherry picking behaviour will enable retailers to obtain a higher share of disposable income from even price-sensitive shoppers, while at the same time charging higher prices. Recent studies indicate that effective cherry picking entails saving costs through price searching over time, price searching across stores, or both. This study examines the relationship between cherry picking and the distance that consumers travel to do grocery shopping. Interviews were conducted at ten different retail outlets over three days, and the results show that there is a highly significant correlation between cherry picking and the distance that consumers travel to do grocery shopping. These results should help retailers to benefit from cherry picking by taking a proactive approach to store switching and store location, two of the main influences on cherry picking behaviour.
\end{abstract}

JEL D91

\section{1}

\section{Introduction}

Retailers know the cherry-picking consumer as a shopper who goes from store to store, buying only items that are specially priced. This perception raises various questions for a retailer: who are cherry pickers? how do they behave? and how does this behaviour impact on retailers? Secondary research conducted by Urbany, Dickson and Sawyer (2000) and Fox and Hoch (2003) show that customers are loyal to stores for many different reasons: from choice, because they feel that they and the store have invested time and effort in building a relationship, because their needs are met or exceeded, or because the relationship is profitable to both sides. A number of factors influence the loyalty and commitment of customers, such as the quality and value of a store's core offering, levels of customer satisfaction, 'elasticity' inherent in the sector or product category, other competitors in the market, and various social, demographic and geographical influences.
The aim of this article is to examine the correlation between cherry picking and the distance that consumers travel to do grocery shopping, to find out whether geographical influences play a role in customer behaviour concerning store switching and location.

Crocker (2005) define cherry picking as 'selecting the best or most desirable'. The term is used to describe both buyer and seller behaviour: it can describe sellers who are selective about which customers they serve, or the behaviour of buyers who are selective about which products or services they purchase at what locations and prices. In both seller and buyer contexts, cherry pickers are opportunistic, taking the best and leaving the rest, according to Alba, Mela, Shimp and Urbany (2003).

This article focuses on the buyer-side of cherry picking in the context of grocery shopping and compares the behaviour of consumers who switch stores and store location and investigates whether geographical influences, such as store location and clustering of stores, play a role in customer behaviour. 
A literature review is first carried out, then the problem statement and the study's specific research objectives outlined, the results of the study presented and recommendations made. The research will also suggest opportunities for future research.

\section{2}

\section{Reasons for this study}

Limited research has been conducted into cherry picking, store switching and the influence of store location on both of these in the marketing and retail sector. This is evident in the limited knowledge available in the literature about store switching and location behaviour. This study attempts to clarify certain perceptions concerning store switching and location behaviour to establish whether a relationship exists between cherry picking and the distance that consumers travel to do grocery shopping.

3

\section{Study objectives}

Retailers can be severely affected by cherry picking and store switching and need to thoroughly understand what influences such behaviour if they are to maintain a substantial competitive advantage in the retail market. To achieve the objectives of this study, the main aim of this article is to determine firstly whether there is a correlation between cherry picking and the distance that consumers travel to do grocery shopping and secondly whether geographical influences particularly store location play a role in customer store switching behaviour. To attain these objectives, the following hypotheses can be drawn:

$\mathrm{H}_{1}$ : There is a correlation between cherry picking and the distance that consumers travel to do grocery shopping.

$\mathrm{H}_{2}$ : There is a significant relationship between store switching and store location.
4

\section{Limitations of the study}

The demographic profile of the respondents is not representative of the broader South African context. This could be attributed to the context of the study, the greater Tshwane area, and the specific malls targeted during data collection.

\section{5}

\section{Literature review}

The relevant literature will be briefly discussed under the headings of cherry picking and customer loyalty, store switching and location, and cherry picking and distance travelled.

\subsection{Cherry picking and customer loyalty}

Cherry picking means taking the best and leaving the rest (Fox \& Hoch, 2003). This behaviour occurs of course to various degrees along a continuum, much like a shopper's degree of price sensitivity. For clarity's sake, therefore, a shopping trip is classified as cherry picking if two or more grocery stores are visited on the same day. As mentioned above, customers are loyal for different reasons, including:

- choice,

- a feeling that time and effort have been invested in building a relationship,

- the meeting or exceeding of their needs, and

- a relationship that is profitable to both sides.

This paper focuses on buyer-side cherry picking in the context of grocery shopping and compares the behaviour of consumers who cherry pick by switching grocery stores with the location of these stores. In the literature, economic search theory predicts that buyers' propensity to cherry pick will be inversely related to their transaction and inventory holding costs, because of both demographic (e.g., working women, age, income, household size, home ownership) and geographical factors (distance between nearby stores). 


\subsection{Store switching and location}

Some studies (e.g. Fox \& Hoch, 2003; Carter, 2005; Halbritter, 2005) suggest that consumers tend to cherry pick in two related ways. First, each week they can buy their entire market basket at the retailer where they get the best deals. If competing retailers promote nonidentical items, store switching across weeks increases compared to consumers loyal to a particular store. Moreover, the transaction costs associated with switching stores across weeks do not seem to be much greater than those incurred by store-loyal shoppers, assuming that travel costs to the stores from which they choose are similar and that consumers switch often enough to be adequately familiar with store layouts. Second, shoppers can engage in a more extreme form of cherry picking where store switching occurs within the same week. In this case, customers split their market basket across stores within a week (potentially on the same day) to benefit from deals offered by different stores.

Gauri, Sudhir and Talukdar (2005) observe three types of cherry pickers, namely:

- Shoppers who cherry pick by price searching over time: these consumers may be store loyal but are still price sensitive and so delay their shopping over time while still doing it at the same store.

- Customers who cherry pick by price searching across stores: these customers still do all their shopping on one day but, based on price, shop across different stores.

- Customers who cherry pick by switching both across stores and over time: these customers will search for the best deal within the same store over time, and between stores on the same day.

What constitutes cherry picking behaviour is central to this study and our definition of such behaviour will form the foundation for all the findings of this research.

\subsection{Distance travelled by the shopper}

The cost of shopping also increases with the distance the shopper must travel to the store, reflecting the time and/or direct cost of transportation. We cannot measure travel distance for specific shopping trips, however, because we do not know with certainty where each trip originates and what route the shopper takes. Thus we must treat travel distance as a household trait, rather than a state variable. If the simplifying assumptions are made that (i) all trips originate from home, and (ii) the shopper travels from the first store visited directly to subsequent stores without intermediate stops, then the distance between the closest and nextclosest stores reflects the cost of an incremental store visit. We can therefore hypothesize that there is a negative relationship between the probability of cherry picking on a given shopping trip and the distance between the closest and next-closest stores to the consumer's home.

Loyalty cards and their influence on store switching and store location do not seem to be the prime reason for choosing a particular store, while factors such as price, quality, service and convenience contribute more to fostering loyal shoppers, according to consumer research in the food and grocery sector. A number of factors influence the loyalty and commitment of customers, such as quality and value of a store's core offering, levels of customer satisfaction, the 'elasticity' inherent in the sector or product category, other competitors in the market, and various social, demographic and geographical influences.

To achieve the objectives of this study, the main aim of this article is to determine firstly whether a relationship exists between cherry picking and the distance that consumers travel to do grocery shopping and secondly whether geographical influences, particularly store location, play a role in customer store switching behaviour. The true definition of cherry pickers needed to be studied. Therefore the following hypotheses are formulated:

$\mathrm{H}_{1}$ : There is a significant relationship between store switching and store location.

$\mathrm{H}_{2}$ : There is a correlation between cherry picking and the distance that consumers travel to do grocery shopping.

The research methodology used in this research will now be explained. 


\section{6}

\section{Research methodology}

Secondary and primary sources were used for the necessary information. The main secondary sources were journals, articles, press reports and books. The main primary source of data was questionnaires. The sampling and data collection methods, measurement instruments and inferential statistics of the study can be briefly discussed.

\subsection{Sampling}

The target population of this study was grocery shoppers, where grocery shopping is defined as shopping for food, toiletries and detergents excluding bread and milk. These sample elements were targeted in the context of shopping malls through the use of mall intercepts and interviewer-administered personal interviews. Mall intercept surveys are a variation of in-house personal interviewing, and involve engaging shoppers in a shopping centre, qualifying them and thereafter conducting the interview. This form of survey is more flexible than in-house personal surveys. The interviewer also has full control of the interviewing environment. This form of interviewing is very useful when testing a concept like cherry picking (Tustin, Ligthelm, Martins \& Van Wyk, 2005).

Leedy (2004: 18) distinguishes between probability and non-probability sampling. In probability sampling, the probability that any member of the population will be included in the sample can be determined, while in nonprobability sampling, this probability cannot be specified. In this study, probability sampling was used. A sampling frame was obtained of shopping malls in the greater Tshwane area and specific shopping malls selected based on convenience and a wide LSM (Living Standard Measure) spread. A relatively representative sample was obtained through targeting shopping malls for various LSM groups in different areas of Tshwane.

A realised sample size of 176 was obtained from a target sample size of 250, with 100 per cent of the questionnaires usable. This perfect record can be attributed to the use of personal interviews as the data collection method, as will now be briefly discussed.

\subsection{Data collection}

The questionnaire was pre-tested in ten quasiinterviews with respondents selected based on convenience. For the actual interviews, respondents were scanned and only 'main family grocery shoppers' were allowed to participate. Data was collected over three days at ten different shopping malls, using personal interviews as a survey method. A wide spread of respondents was targeted by conducting the survey at different times each day, namely morning, afternoon and early evening. Personal interview is generally regarded as the best survey method in testing concepts (Tustin et al., 2005) such cherry picking. In-house interviewers, knowledgeable in the field and from an academic background, were used to decrease the likelihood of interviewer bias. No incentives were offered to boost response rate.

\subsection{Measurement instruments}

Nominal data, in this case demographic variables such as respondent income and age, were investigated using direct questions. Location, the main construct of this study, was measured using a Likert-type scale. The basic scale design consisted of five scale points with labels ranging from strongly agree to strongly disagree, and 11 scale items. This scale was found to be highly reliable, with a Cronbach's Alpha of 0.7 . The constructs measuring cherry picking behaviour as price searching across time and price searching across stores were measured using similar scales with five scale items. These two scales were also found to be reliable. No items on any of these scales were reverse scored.

\subsection{Inferential statistics}

In addition to describing the sample data using common indicators such as mean, standard deviation and proportion, this study makes inferences about the population as a whole based on what was observed in the sample. Inferential statistics allow researchers to make 
inferences concerning the true differences in a population (Tustin et al., 2005).

The data set of questionnaire results is augmented by data reflecting the locations of the households of the respondents and the grocery stores these respondents visit. This data allows us to compute travel distances both from the shoppers' homes to stores and between stores in order to assess the relationships between these geographic variables and cherry picking. The following null and alternative hypotheses can be formulated:

$\mathrm{H}_{0}: \mu \neq 10 \mathrm{~km}$

$\mathrm{H}_{2}: \mu=10 \mathrm{~km}$

The research findings will be discussed next.

\section{7}

\section{Research findings}

Descriptive and inferential statistics were used to test the hypotheses of this study.

\subsection{Descriptive statistics}

The sample in this study consisted of 67 per cent females and 33 per cent males of an average age of between 24 and 28 years. The language of preference was relatively diverse, with Afrikaans (40 per cent), English (17 per cent) and North Sotho (15 per cent) the most common languages. This demographic variable is of course greatly influenced by the site of the research, namely Gauteng province, where North Sotho is a commonly spoken language, and Pretoria city, where Afrikaans is very common. Also important is the race of the respondents, 45 per cent African, 52 per cent white, 2 per cent coloured and 1 per cent Indian.

Two important characteristics are evident from the results. First, 20 per cent of the sample does not cherry pick at all. Second, the distribution is heavily skewed with a long right tail. Thus, most households are on the low end of the cherrypicking continuum. The mean and median of the per cent cherry-picking distribution are 7.7 and 4.2 per cent, respectively, with households in the top decile cherry picking on only 32.0 per cent of shopping trips. Though they may not seem compellingly large, these statistics include the fact that each cherry-picking trip is made up of multiple store visits. If we consider the distribution of store visits, which reflects retailer traffic counts, we find that the mean and median are 13.2 per cent and 8.2 per cent respectively, with the top decile of cherry picks on 49.3 per cent of visits.

\section{Cherry picking behaviour}

As described earlier, cherry picking occurs when a consumer visits two or more grocery stores on the same day. The results of the study are shown in Figure 1.

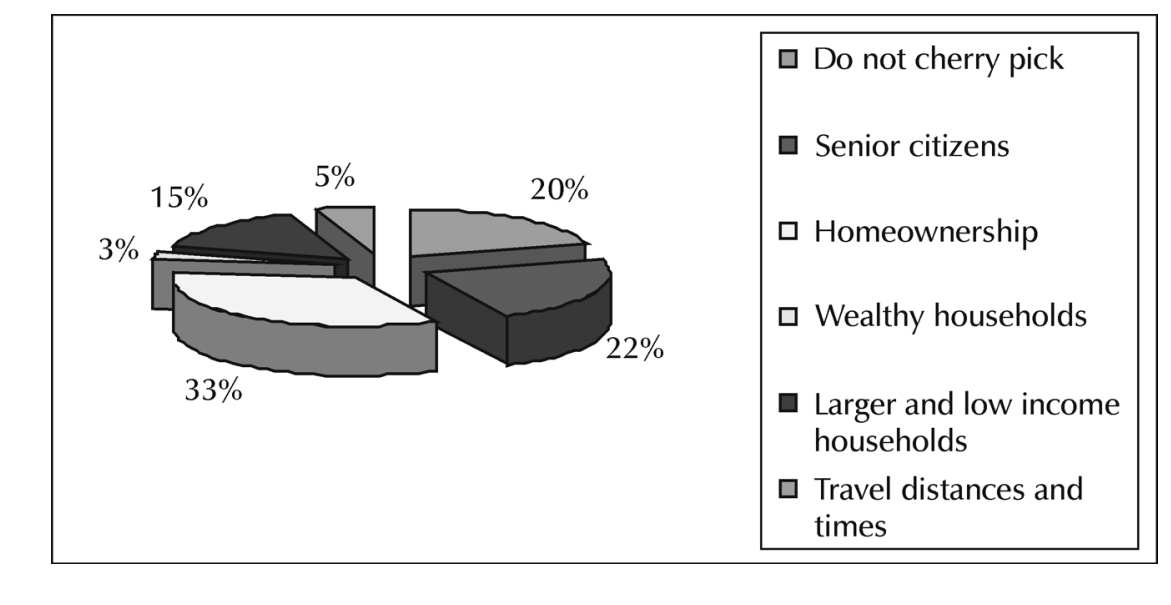

Figure 1

Cherry picking behaviour 
Figure 1 shows the distribution across households of cherry picking trips as a percentage of all the household's shopping trips. 20 per cent of the sample does not cherry pick. Households are less likely to cherry pick if the shopper is an working adult female (only five per cent of the sample) presumably because these women's time is particularly valuable. Senior citizens ( $\geq 65$ years old) are less likely to be employed outside of the home and so have more time to invest in shopping. Therefore if there is a senior citizen in the household cherry picking increases to 22 per cent.

Homeownership implies greater inventory carrying capability, and so that home-owning households can afford to cherry pick to take advantage of the discounts available at various stores because they have more opportunity to accelerate purchases by forward buying. As indicated in Figure 1, homeownership increases the propensity to cherry pick to about 33 per cent.

Wealthy households are assumed to have higher opportunity costs and to be less pricesensitive. Indeed, high household income has a negative impact on per cent cherry picking, with only three per cent of these respondents' indicating that they sometimes cherry pick. In contrast, lower income or large households are assumed to be more price-sensitive and will switch stores more often, because they have to spend a greater proportion of their income on groceries (budget constraint). 15 per cent of the respondents indicated that they cherry pick because they have greater returns to price search by virtue of purchasing scale.

Travel distances and times also influence cherry picking. Although distance to nearest store from home does not seem to affect cherry picking, distance from the nearest to next-nearest store is negatively correlated to such behaviour. This suggests that households consider the incremental cost of the extra store visit (which can be very low if nearby stores are close together, but more costly if they are not) against the expected benefit of the additional discounts available if that extra store visit is made. Figure 1 shows that each extra kilometre between stores decreases the per cent of cherry picking by about five per cent.

\section{Consumer loyalty}

As noted in the literature review, customers are loyal for different reasons; some feel they have invested time and effort in building a relationship with the staff of a particular retailer. Question 4 of the questionnaire asked how loyal respondents are to their grocery store. The responses are indicated in table 1.

Table 1

Descriptive data of the customer

\begin{tabular}{|ll|c|c|c|}
\hline & & Frequency & \% & cumulative (\%) \\
\hline Valid & not loyal & 17 & 10.12 & 10.12 \\
& indifferent & 34 & 25.6 & 35.18 \\
& very loyal & 108 & 64.29 & 99.47 \\
\hline & Total & 168 & 100.0 & 100.0 \\
\hline Missing & system & 8 & & \\
\hline Total & & 176 & & \\
\hline
\end{tabular}

Table 1 indicates that 64.29 per cent of the respondents are loyal to their stores, and only 10.12 per cent are not loyal. Store location will be discussed next.

\section{Store location}

Most respondents (65 per cent) agreed that they remain loyal to the store most conveniently located and will not change stores even when a store further from them offers a product at a cheaper price than their regular store. This 
response indicates that these respondents will not cherry pick even if another more distant store offers lower prices.

\section{Store switching}

The respondents were asked whether they would price shop across stores, that is, switch from their usual store if lower prices were offered at another store. 34.1 per cent strongly disagreed that they would switch, 32 per cent agreed that they would switch and 23.8 per cent indicated that they are indifferent to lower prices and store switching and would not switch stores.

This question was further analysed to establish whether race has an influence on the respondent's perceptions concerning price shopping across stores. The respondents were grouped into African, white, coloured and Indian subgroups. More respondents of the African group, 47.4 per cent, strongly disagreed that they would price shop across stores than did respondents from the white group (42.2 per cent). 33.3 per cent of the coloured group's respondents strongly disagreed that they would price shop across stores. The results for a positive response to price shopping across stores are interesting, with 100 per cent of the Indian group, 34.4 per cent of the African group, 31.1 per cent of the white group and none of the coloured group agreeing that they would price shop across stores. The 23.8 per cent of the respondents who were indifferent to price shopping across stores consists of 19.2 per cent of the African group, 26.7 per cent of the white group, 66.7 per cent of the coloured group and none of Indian group.

These results suggest that respondents of the African group are less likely to price shop across stores than any of the other groups; thus this group is less prepared to cherry pick than any of the other groups.

$\mathrm{H}_{1}=$ There is a significant correlation between store switching and store location.

The response to this hypothesis is shown in Table 2.

\section{Table 2}

Pearson correlation

\begin{tabular}{|c|c|c|c|}
\hline & & $\begin{array}{l}\text { (STORE IN Q5) is } \\
\text { conveniently located }\end{array}$ & $\begin{array}{c}\text { Total: price shop across } \\
\text { stores }\end{array}$ \\
\hline \multirow{3}{*}{$\begin{array}{l}\text { (STORE IN Q5) is } \\
\text { conveniently located }\end{array}$} & Pearson correlation & 1 & 0.073 \\
\hline & Sig. (2-tailed) & . & 0.348 \\
\hline & $\mathrm{N}$ & 167 & 166 \\
\hline \multirow{3}{*}{$\begin{array}{l}\text { Total: price shop across } \\
\text { stores }\end{array}$} & Pearson correlation & 0.073 & 1 \\
\hline & Sig. (2-tailed) & 0.348 & . \\
\hline & $\mathrm{N}$ & 166 & 175 \\
\hline
\end{tabular}

Table 2 shows that the Pearson correlation indicates a perfect correlation of 1 at a significance level of 0.05 2-tailed. The z-test, showed that $\mathrm{H} 01$ should be rejected, and $\mathrm{Ha} 1$ thus accepted. Therefore, we can conclude that there is a significant correlation between store switching and store location.

The study also aimed to establish how far respondents would be prepared to travel for products on special or offered at lower prices.
The respondents who would price shop across stores indicated that they would be prepared to travel $10 \mathrm{~km}$ for lower priced products.

The study aims to show that there is a significant correlation between cherry picking and the distance that consumers travel to do grocery shopping. The following hypotheses were formulated.

$\mathrm{H}_{02}: \mu \neq 10 \mathrm{~km}$

$\mathrm{H}_{\mathrm{a} 2}: \mu=10 \mathrm{~km}$ 
The z-test showed that $\mathrm{H}_{02}$ should be rejected and $\mathrm{H}_{\mathrm{a} 2}$ thus accepted. Therefore, we can conlude that there is a significant correlation between cherry picking and the distance that consumers travel to do grocery shopping.

\section{8}

\section{Discussion}

This study aimed to examine the relationship between cherry picking and the distance that consumers travel to do grocery shopping, and to determine whether geographical factors, particularly store location, influence customer store-switching behaviour.

Data collected from Tshwane consumers indicate that there is a relationship between cherry picking and the distance that consumers are prepared to travel to do grocery shopping, and that location does influence cherry picking behaviour.

\subsection{Summary of research findings}

Most respondents indicate an average income of between R5 000 and R15 000 (43 per cent), or less (39 per cent). The average amount that respondents spend on grocery shopping is R1 560. On average, those who do cherry pick are prepared to travel $10 \mathrm{~km}$ for products on special or offered at lower prices.

\subsection{Managerial implications}

Knowledge about store switching and the effect location has on this behaviour can help retailers to get more sales from price-sensitive shoppers and increase their share of the market. Retailers need to know how cherry picking affects them. This depends on whether a store is the shopper's primary grocery outlet or a secondary grocery outlet. A primary store is the grocery chain at which the household spends the most money over a two-year period, and all other stores can be designated secondary outlets. It is one thing to be a shopper's primary store, and every so often, when the cherry shopper picks your competition, lose a bit of money, and quite another to be that secondary store, and only to get occasional visits. Not only do shoppers not spend as much in a secondary store, but also, when they do visit, they opportunistically buy more sale items. However, households that cherry pick more also tend to have more family members and so consume more goods, so overall cherry picking households generate more retailer revenue than do non-cherry picking households. The cherry picking households in this study spend R1 576/month on average, and the households that cherry pick less frequently spend only R1 498/month.

Knowledge of cherry picking behaviour is also helpful to manufacturers, since most of the saving made through cherry picking comes from buying items on promotion, so ultimately this saving is subsidised by manufacturer discounting. Thus the burden of cherry picking is borne by both retailer and manufacturer, since manufacturers sell more on deal because of customer demand. Also, cherry pickers are not brand loyal.

The results indicate that if retailers advertise products, opportunism in the form of cherry picking is inevitable. While retailers must make broad offerings, they can also find ways to exploit this tendency. Cherry pickers tend to opportunistically shop at the second store they visit in a single day, buying less but at a higher discount. Cherry pickers tend to be more vigilant shoppers who pay lower prices, but are nevertheless a segment large enough to matter to retailers. Fox (2005) advises retailers not to marginalise cherry pickers, whose behaviour simply highlights the effects of price competition with other retailers. All retailers, therefore, must strive to have the most attractive offers and weekly ads. Retailers should offer things people want and care about, and stay competitive in the process. The current study shows that not much research has been done in South Africa on cherry picking.

\subsection{Recommendations for future research}

This study has found that insufficient research has been done on the loyalty card system and its influence on cherry picking and store switching. Future research could focus on this area. Future research could also include a comparative 
study between South Africa and the United States of America to determine whether South Africans or Americans are more prone to cherry picking.

\section{9}

\section{References}

1 ALBA, J.W.; MELA, C.F.; SHRIMP, T.A. \& URBANY, J.E. (2003) "The effect of discount frequency and depth on consumer price judgements", Journal of Consumer Research, 26: 99-114.

2 CARTER, B. (2005) "The facts of cherry picking", International Marketing Journal, www.findarticles. com. (Accessed 24 February 2006).

3 CROCKER, D. (2005) “Cherry picking”, www. dnso.org. (Accessed 25 February 2006).
4 FOX, E.J. \& HOCH, S.J. (2003) "Cherry picking”, Journal of Marketing, 69(1) http://proquest.umi. com. (Accessed 24 January 2006).

5 GAURI, D.K, SUDHIR, K. \& TALUKDAR, D. (2005) "'When' and 'where' to cherry pick? The temporal and spatial dimensions of price search". International Marketing Journal, www.google.com (Accessed 24 January 2006).

6 HALBRITTER, J. (2005) "Cherry picking, the way to go", International Marketing Journal www. findarticles.com. (Accessed 25 February 2006).

7 LEEDY, P.D. (2004) Practical Research (6 ${ }^{\text {th }}$ ed.) Macmillan: London.

8 TUSTIN, D.; LIGTHELM, A.; MARTINS, D. \& VAN WYK, J. (2005) Marketing Research in Practise, UNISA University Press: Pretoria.

9 URBANY, J.E.; DICKSON, P.E. \& SAWYER, A.G. (2000) "Insights into cross- and within-store price search: retailer estimates vs consumer selfreports", Journal of Retailing, 76(2): 243-258. 